\title{
Lean mass, muscle strength, and physical function in a diverse population of men: a population-based cross-sectional study
}

\author{
Andre B Araujo ${ }^{1 *}$, Gretchen R Chiu', Varant Kupelian', Susan A Hall1', Rachel E Williams², Richard V Clark ${ }^{3}$, \\ John B McKinlay ${ }^{1}$
}

\begin{abstract}
Background: Age-related declines in lean body mass appear to be more rapid in men than in women but our understanding of muscle mass and function among different subgroups of men and their changes with age is quite limited. The objective of this analysis is to examine racial/ethnic differences and racial/ethnic group-specific cross-sectional age differences in measures of muscle mass, muscle strength, and physical function among men.

Methods: Data were obtained from the Boston Area Community Health/Bone (BACH/Bone) Survey, a populationbased, cross-sectional, observational survey. Subjects included 1,157 black, Hispanic, and white randomly-selected Boston men ages 30-79 y. Lean mass was assessed by dual-energy $x$-ray absorptiometry. Upper extremity (grip) strength was assessed with a hand dynamometer and lower extremity physical function was derived from walk and chair stand tests. Upper extremity strength and lower extremity physical function were also indexed by lean mass and lean mass was indexed by the square of height.
\end{abstract}

Results: Mean age of the sample was $47.5 \mathrm{y}$. Substantial cross-sectional age differences in grip strength and physical function were consistent across race/ethnicity. Racial/ethnic differences, with and without adjustment for covariates, were evident in all outcomes except grip strength. Racial differences in lean mass did not translate into parallel differences in physical function. For instance, multivariate modeling (with adjustments for age, height, fat mass, self-rated health and physical activity) indicated that whereas total body lean mass was $2.43 \mathrm{~kg}$ (approximately 5\%) higher in black compared with white men, black men had a physical function score that was approximately 20\% lower than white men.

Conclusions: In spite of lower levels of lean mass, the higher levels of physical function observed among white compared with non-white men in this study appear to be broadly consistent with known racial/ethnic differences in outcomes.

\section{Background}

The aging process is accompanied by substantial changes in body composition, such as increases in fat mass [1] and loss of lean body mass [2]. The age-related decline in lean body mass that affects functional capacity, referred to as sarcopenia, [3] appears to be more rapid in men than in women $[4,5]$. Nonetheless, our understanding of muscle mass and function among different population subgroups of men and their changes

\footnotetext{
* Correspondence: aaraujo@neriscience.com

1 New England Research Institutes, Inc., Watertown, MA, USA

Full list of author information is available at the end of the article
}

with age is quite limited. For instance, relatively little is known about potential racial/ethnic differences among men. This is important since loss of muscle is strongly linked with disability, [6] which has further consequences for outcomes which are known to vary with race/ethnicity, including falls, osteoporotic fracture, quality of life, mortality, and health care expenditures [7-15]. Given the aging of the worldwide population, the public health and economic consequences of loss of muscle function will only increase unless strategies are developed to reduce its occurrence.

(C) 2010 Araujo et al; licensee BioMed Central Ltd. This is an Open Access article distributed under the terms of the Creative Commons 
The objective of this analysis is to examine racial/ethnic differences and racial/ethnic group-specific crosssectional age differences in measures of muscle mass, muscle strength, and physical function in a racially/ethnically diverse population-based sample of men from Boston.

\section{Methods}

\section{Study sample}

Data were obtained from men enrolled in the Boston Area Community Health/Bone (BACH/Bone) Survey, which is a cross-sectional observational study of skeletal health and related outcomes in 1,219 (of 1,877 eligible, $65 \%$ response rate) randomly selected black, Hispanic, and white male Boston, MA residents aged 30 to $79 \mathrm{y}$ [16]. Persons of other racial/ethnic backgrounds were not enrolled. BACH/Bone Survey subjects were a subset of 2,301 men previously enrolled in the parent Boston Area Community Health (BACH) Survey; full details of the $\mathrm{BACH}$ survey have been published previously [17]. Study protocols were approved by Institutional Review Boards at New England Research Institutes (NERI) and Boston University School of Medicine (BUSM). All subjects gave written informed consent separately for participation in each study.

\section{Data collection}

Trained staff at NERI and the BUSM's General Clinical Research Center (GCRC) conducted interviews and measurements for $\mathrm{BACH}$ and $\mathrm{BACH} / \mathrm{Bone}$, respectively. Data collection for $\mathrm{BACH}$ generally occurred in subjects' homes while data collection in $\mathrm{BACH} /$ Bone occurred at the BUSM GCRC. Age and self-rated health were obtained by self-report. Physical activity level was measured using the Physical Activity for the Elderly (PASE) scale [18]. Frequency and duration of leisure activities, paid or unpaid work (hours/week), and housework and similar duties (yes/no) over the past week were recorded for each subject. The PASE score was computed by multiplying the amount of time spent in each activity (hours/week) or participation (yes/no) in each activity by empirical item weights (derived from regressions of component scores developed from a 3-day physical activity monitor, 3-day physical activity diary, and a global self-report of physical activity on responses to the PASE in a communitydwelling sample of 277 older adults [18]) and summing over all activities. Measurements of subjects' height and weight were obtained using a stadiometer (Seca Corp., Hanover, MD) and digital scale (Tanita, Arlington Heights, IL), respectively. Body mass index (BMI) was calculated from by dividing measured weight $(\mathrm{kg})$ by the square of measured height $\left(\mathrm{m}^{2}\right)$.

\section{Measures of body composition}

Measurements of lean mass and fat mass were obtained from whole body dual energy $\mathrm{x}$-ray absorptiometry (DXA) scans using a QDR $4500 \mathrm{~W}$ densitometer (Hologic, Inc., Waltham, MA) located at the BUSM GCRC. All mass quantities reported here exclude the head. Lean mass was calculated by subtracting bone mineral mass from non-fat mass. The DXA system was monitored weekly for drift.

\section{Measures of strength}

$\mathrm{BACH} /$ Bone has measures of subjects' upper and lower extremity strength/physical function. Upper extremity strength was assessed by hand grip strength. This was measured using a Jamar Hydraulic Hand Dynamometer (Sammons Preston, Bolingbrook, IL), which measures isometric grip force. Subjects were instructed to exert maximum effort for three seconds during two trials, each separated by a 1 -min rest. The maximum result was used for analysis. Lower extremity strength was assessed by a chair stand test (time to stand up and sit down 5 times) and a walking test (time to walk $50 \mathrm{ft}$ ) [19]. Following a previous study, [19] we created a lower extremity composite physical function variable. Those who could not complete the test were assigned a score of 0 . Those completing the walk and chair stand tests were assigned scores of 1-4, corresponding to the quartiles (derived from our population) of speeds in completing each task, with the fastest speeds scored 4 . The cutpoints for walking speed were as follows: quartile $1,<1.19 \mathrm{~m} / \mathrm{s}$; quartile 2 , $1.19-1.30 \mathrm{~m} / \mathrm{s}$; quartile $3,1.31-1.40 \mathrm{~m} / \mathrm{s}$; quartile $4, \geq 1.41$ $\mathrm{m} / \mathrm{s}$. The cutpoints for chair stand speed were quartile 1 , $<0.314$ stands/s; quartile 2, 0.314-0.360 stands/s; quartile $3,0.361-0.430$ stands/s; quartile $4, \geq 0.431$ stands/s. Only one subject was not able to complete the walk task, so we included that subject with those who were in the slowest quartile of walking speed and reassigned the walking speed quartiles to scores $0-3$. The two items were summed to a final score with possible range of 0 to 7 , with higher scores indicating better lower extremity function.

\section{Indexed outcomes}

Outcomes were indexed by either regional lean mass or the square of height as appropriate. Lean mass was divided by the square of height in meters to yield the lean mass index (LMI). Additional measures of relative strength in the upper and lower extremities was estimated by dividing upper and lower extremity measures of strength/physical function by their corresponding regional measures of lean mass [20]. Specifically, maximum grip strength was divided by arms lean mass and the lower extremity composite physical function score was divided by legs lean mass. 


\section{Analysis samples}

Of the 1,219 men in $\mathrm{BACH} /$ Bone, 10 men did not have DXA scans performed. Of the remaining 1,209, we excluded 49 who were missing fat or lean mass and three men missing PASE. This left 1,157 men available as a base for analysis. From this base analysis sample, we used the maximum available data for each of the outcome measures: lean mass and lower extremity strength, $\mathrm{N}=1,147$; upper extremity strength, $\mathrm{N}=970$ (54 men were coded as missing due to dynamometer malfunction).

\section{Statistical methodology}

Sampling weights were used to produce estimates for means and percentages that are representative of the black, Hispanic, and white male population in Boston, MA between the ages of 30 and 79 y. Sampling weights account for the design effect of over-sampling of particular age and racial and ethnic groups [21].

Exploratory graphical analysis was conducted using locally weighted linear regression (LOESS) models where non-linear functions are fit to subsets of the data using weighted least squares [22]. Line graphs showing cross-sectional age differences in the main outcomes by race/ethnicity are presented.

Three multivariate linear regression models were constructed for each of the outcome variables: (1) Model 1: adjusted for age, race/ethnicity, and height. (2) Model 2: all variables in Model 1 plus potential confounding influences (fat mass, self-rated health status and physical activity). Smoking and a count of 6 major medical comorbidities were also examined but they made no significant contribution to any of the models. (3) Model 3: all variables in Model 2 plus grip strength, the composite physical function score, or lean mass (for nonindexed outcomes) or grip strength/arms lean mass, composite physical function score/legs lean mass, or lean mass index (for indexed outcomes). For instance, Model 3 with lean mass as the outcome would have included all factors in Model 2, plus grip strength and the composite physical function score. This third set of models was constructed in order to examine which variables differ most between the racial/ethnic groups in the presence of other muscle function variables of interest. Race/ethnicity was placed in each model as a categorical variable. Regression coefficients and 95\% confidence intervals (CI) for black and Hispanic men (using white men as the reference category) were presented. Associations were considered statistically significant if null hypotheses could be rejected at the 0.05 level (twosided). All statistical modeling was conducted using SUDAAN software (Research Triangle Institute, Research Triangle Park, NC).

\section{Results}

The mean age of the sample was $48 \mathrm{y}$. Descriptive statistics for several variables of interest can be found by race/ethnicity in Table 1. Lean mass and grip strength was similar in black and white men, while white men had a $25 \%$ higher average composite physical function score. When these measures were indexed by lean mass black/white differences were accentuated (grip/lean mass: $10 \%$ higher among white men; physical function/ lean mass: $29 \%$ higher among white men). LMI was $5 \%$ higher in black compared with white men. White men also had higher lean mass, grip strength, and composite physical function score when compared to Hispanic men, but these differences were reduced to $<10 \%$ when indexed for height or lean mass.

Figure 1 shows that strong age differences in grip strength (all p <.001), composite physical function score (all $\mathrm{p}<.001$ ), and outcomes indexed by regionspecific lean mass were consistent across race/ethnicity. Age differences in lean mass and LMI were less pronounced but also did not appear to differ appreciably by race/ethnicity. The absence of racial/ethnic differences in age trends in the outcomes was further verified with statistical tests for effect modification by race/ethnicity, none of which were significant (all p > .3). Figure 1 also shows that age differences in grip strength and in lower extremity physical function were more pronounced than their corresponding indicators which were indexed by region-specific lean mass; such was not the case when comparing age differences in lean mass and LMI. For instance, compared to men in their $30 \mathrm{~s}$, men in their $70 \mathrm{~s}$ had $25 \%$ lower grip strength. In contrast, grip strength/arms lean mass was $11 \%$ lower among men in their $70 \mathrm{~s}$. A similar pattern was evident in the lower extremity.

Exploratory scatter plots with LOESS curves were examined for lean mass, strength, and physical function vs. fat mass or weight (data not shown). Overall, fat mass appeared to be most strongly associated with the outcomes of interest. Also, although a slight curvature was observed (e.g., the association of fat mass with grip strength became less pronounced with increasing fat mass), formal statistical testing indicated that quadratic terms for fat mass contributed little to the model.

Results from the multiple linear regression models are depicted in Table 2. Grip strength was not associated with race/ethnicity independent of age, height, fat mass, self-rated health, and physical activity $(\mathrm{p}=.15)$. In contrast, grip strength/arms lean mass differed significantly by race/ethnicity, with higher estimates observed among white compared to black and Hispanic subjects $(\mathrm{p}<.01)$. However, further adjustment for composite physical function score and LMI confounded this 
Table 1 Descriptive statistics ${ }^{a}$ by race/ethnicity $(N=1,157)$

\begin{tabular}{lccccccc}
\hline & \multicolumn{2}{c}{ Black } & \multicolumn{2}{c}{ Hispanic } & \multicolumn{2}{c}{ White } \\
\cline { 2 - 7 } Variable & Mean & (SD) & Mean & (SD) & Mean & (SD) & Comparison ${ }^{\mathbf{b}}$ \\
\hline Lean Mass, kg & 56.35 & $(8.83)$ & 51.82 & $(7.24)$ & 55.43 & $(7.14)$ & $\mathrm{H}<\mathrm{B}, \mathrm{W}$ \\
Arm Lean Mass, kg & 7.84 & $(1.58)$ & 7.05 & $(1.28)$ & 7.05 & $(1.18)$ & $\mathrm{H}, \mathrm{W}<\mathrm{B}$ \\
Leg Lean Mass, kg & 20.21 & $(3.58)$ & 18.06 & $(2.83)$ & 19.40 & $(2.76)$ & $\mathrm{H}<\mathrm{W}<\mathrm{B}$ \\
Grip Strength, kg & 40.83 & $(12.99)$ & 37.59 & $(8.60)$ & 40.24 & $(11.48)$ & $\mathrm{H}<\mathrm{B}, \mathrm{W}$ \\
Composite Physical Function Score & 3.45 & $(1.97)$ & 3.66 & $(1.84)$ & 4.30 & $(1.99)$ & $\mathrm{B}, \mathrm{H}<\mathrm{W}$ \\
Lean Mass Index, kg/m & 18.41 & $(2.34)$ & 17.99 & $(2.21)$ & 17.59 & $(2.02)$ & $\mathrm{H}, \mathrm{W}<\mathrm{B}$ \\
Grip Strength/Arms Lean Mass & 5.21 & $(1.38)$ & 5.40 & $(1.30)$ & 5.71 & $(1.50)$ & $\mathrm{B}, \mathrm{H}<\mathrm{W}$ \\
Composite Physical Function Score/Legs Lean Mass & 0.17 & $(0.10)$ & 0.21 & $(0.11)$ & 0.22 & $(0.11)$ & $\mathrm{B}<\mathrm{H}, \mathrm{W}$ \\
Height, cm & 174.72 & $(7.31)$ & 169.63 & $(6.14)$ & 177.46 & $(6.93)$ & $\mathrm{H}<\mathrm{B}<\mathrm{W}$ \\
Weight, kg & 87.78 & $(16.84)$ & 81.54 & $(14.27)$ & 89.04 & $(14.73)$ & $\mathrm{H}<\mathrm{B}, \mathrm{W}$ \\
BMI, kg/m ${ }^{2}$ & 28.72 & $(5.07)$ & 28.33 & $(4.72)$ & 28.27 & $(4.44)$ & $\mathrm{B}, \mathrm{H}, \mathrm{W}$ \\
Fat Mass, kg & 20.57 & $(9.03)$ & 19.78 & $(7.37)$ & 23.10 & $(8.47)$ & $\mathrm{B}, \mathrm{H}<\mathrm{W}$ \\
Percent Fat Mass & 25.74 & $(7.60)$ & 26.86 & $(6.09)$ & 28.65 & $(6.50)$ & $\mathrm{B}, \mathrm{H}<\mathrm{W}$ \\
\hline
\end{tabular}

${ }^{a}$ All estimates weighted according to Sampling Design (see Methods)

${ }^{b}$ Pairwise comparison, $\mathrm{p}<.05$. B = Black, $\mathrm{H}=$ Hispanic, $\mathrm{W}=$ White

association $(p=.15)$. Values for the composite physical function score and composite physical function score/ legs lean mass were higher in white men, even in the presence of confounders (both $\mathrm{p}<.001$ ) and when further adjusted for grip strength and lean mass or grip strength/arms lean mass and LMI (both $\mathrm{p}<.001$ ). Lean mass and LMI were higher in black $(\mathrm{p}<.001)$ and slightly higher in Hispanic $(\mathrm{p}=.06)$ men compared with white men when adjusted for all confounding influences. It is notable that the regression coefficients in models of lean mass and LMI increased with the addition of control variables to each model, indicating negative confounding on the part of these other variables.

\section{Discussion}

In this population-based survey of diverse men, we find evidence of age and racial/ethnic differences in measures of lean mass and LMI, as well as lower extremity strength and physical function. Overall, more pronounced age differences were observed in strength measures as compared to lean mass and relative measures of strength (i.e., outcomes relative to the amount of regional lean tissue). Observed racial/ethnic differences indicate higher lean mass among black and Hispanic compared with white men but surprisingly, lower levels of physical function among these black and Hispanic men.

Previous studies have shown that there are racial disparities in disability, with lower rates generally reported among whites $[23,24]$. Although studies of diverse populations of men are rare, the few data on age changes in muscle function in such populations show complexities similar to those reported in the current study. Consistent with our study, data from the Chicago Health and Aging Project indicate that black men and women have lower physical function compared with white men and women [25]. They also observed that this difference increases over time, particularly among women. Data from the Third National Health and Nutrition Examination Survey indicate that while black men exhibit elevated lean mass as compared to white men in young adulthood, they also show accelerated loss of lean mass after age $50[26,27]$. Data from the current study are similar insofar as black men have higher lean mass compared with white men, but age differences by race/ethnicity were not observed in the current study. In the Health, Aging, and Body Composition Study black subjects had greater appendicular lean mass and strength, but also lower muscle quality than whites [20]. The data reported herein are quite consistent with these results, insofar as we observed that white men had lower lean mass but greater physical function than non-white men. The reasons for this apparent contradiction are not immediately clear, but one could speculate that this could relate to differences in muscle quality, or the strength exerted for each unit of muscle, between racial/ ethnic groups. Unfortunately, this study did not collect the data required to address this issue. Nonetheless, the finding that higher lean mass among non-white men does not translate into better grip strength or physical function is broadly consistent with general findings of worse health outcomes (morbidity, mortality) among non-white men. Finally, while these data do not necessarily rule out a role for muscle function as determinants of racial/ethnic differences in fracture risk, they emphasize the central role of racial/ethnic differences of bone strength $[16,28,29]$.

Contributors to muscle strength and physical function are not well understood. Studies show that age-related 


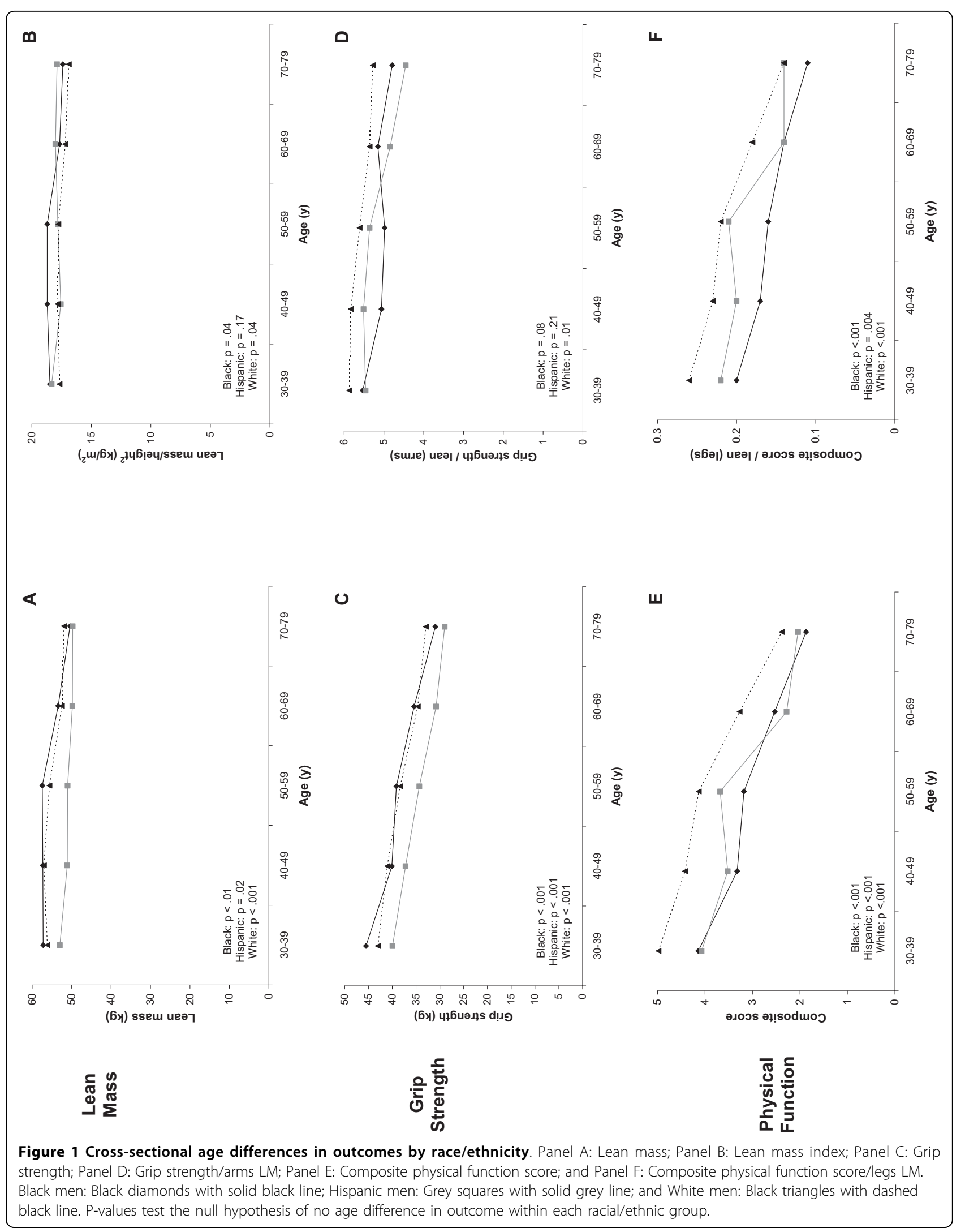




\begin{tabular}{|c|c|c|c|}
\hline & \multicolumn{2}{|c|}{ Regression coefficient vs. White $(95 \% \mathrm{Cl})$} & \multirow[b]{2}{*}{ Model $\mathrm{R}^{2}$} \\
\hline & Black & Hispanic & \\
\hline \multicolumn{4}{|c|}{ Lean Mass (kg) } \\
\hline Model $1^{\mathrm{c}}$ & $2.43(1.12,3.73)^{* * *}$ & $0.19(-1.23,1.60)$ & 0.3094 \\
\hline Model $2^{\mathrm{d}}$ & $3.41(2.39,4.44)^{* * *}$ & $1.06(-0.05,2.16)$ & 0.5546 \\
\hline Model $3^{\mathrm{e}}$ & $3.78(2.78,4.77)^{* * *}$ & $1.63(0.40,2.86)^{* *}$ & 0.6087 \\
\hline \multicolumn{4}{|c|}{ Grip Strength (kg) ${ }^{b}$} \\
\hline Model $1^{\mathrm{c}}$ & $1.60(-1.67,4.86)$ & $-1.06(-3.92,1.80)$ & 0.1306 \\
\hline Model $2^{d}$ & $1.75(-1.57,5.07)$ & $-0.98(-4.08,2.11)$ & 0.1620 \\
\hline Model $3^{e}$ & $0.87(-2.07,3.81)$ & $-0.90(-3.64,1.85)$ & 0.2781 \\
\hline \multicolumn{4}{|c|}{ Composite Physical Function Score } \\
\hline Model $1^{c}$ & $-0.89(-1.22,-0.56)^{* * *}$ & $-0.94(-1.41,-0.47)^{* * *}$ & 0.1600 \\
\hline Model $2^{\mathrm{d}}$ & $-0.85(-1.20,-0.49)^{* * *}$ & $-0.87(-1.38,-0.35)^{* * *}$ & 0.2323 \\
\hline Model $3^{\mathrm{e}}$ & $-1.04(-1.40,-0.68)^{* * *}$ & $-0.79(-1.25,-0.33)^{* * *}$ & 0.2671 \\
\hline \multicolumn{4}{|c|}{ Lean Mass Index $\left(\mathrm{kg} / \mathrm{m}^{2}\right)^{\mathrm{g}}$} \\
\hline Model $1^{\mathrm{c}}$ & $0.82(0.40,1.23)^{* * *}$ & $0.23(-0.21,0.67)$ & 0.0411 \\
\hline Model $2^{d}$ & $1.18(0.86,1.50)$ & $0.69(0.33,1.04)^{* * *}$ & 0.3630 \\
\hline Model $3^{f}$ & $1.25(0.89,1.61)^{* * *}$ & $0.70(0.30,1.10)^{* * *}$ & 0.3914 \\
\hline \multicolumn{4}{|c|}{ Grip Strength/Arms Lean Mass } \\
\hline Model $1^{c}$ & $-0.54(-0.91,-0.18)^{* *}$ & $-0.50(-0.87,-0.12)^{* *}$ & 0.0450 \\
\hline Model $2^{d}$ & $-0.57(-0.95,-0.20)^{* *}$ & $-0.52(-0.92,-0.13)^{* *}$ & 0.0686 \\
\hline Model $3^{f}$ & $-0.23(-0.59,0.14)$ & $-0.36(-0.73,0.01)$ & 0.1396 \\
\hline \multicolumn{4}{|c|}{ Composite Physical Function Score/Legs Lean Mass } \\
\hline Model $1^{c}$ & $-0.058(-0.077,-0.040)^{* * *}$ & $-0.046(-0.074,-0.019)^{* *}$ & 0.1499 \\
\hline Model $2^{d}$ & $-0.060(-0.079,-0.040)^{* * *}$ & $-0.046(-0.075,-0.016)^{* *}$ & 0.2567 \\
\hline Model $3^{f}$ & $-0.052(-0.071,-0.0327)^{* * *}$ & $-0.0346(-0.059,-0.010)^{* *}$ & 0.2783 \\
\hline \multicolumn{4}{|c|}{ a All estimates weighted according to Sampling Design (see Methods) } \\
\hline \multirow{2}{*}{\multicolumn{4}{|c|}{${ }^{b}$ Models including grip strength or grip strength/LM have $N=970$. Other models, $N=1,147$. }} \\
\hline ' Model 1: Controlled for age and height & & & \\
\hline \multicolumn{4}{|c|}{ d Model 2: Controlled for age, height, fat mass, self-rated health and physical activity } \\
\hline \multicolumn{4}{|c|}{$\begin{array}{l}\text { e Model 3: Controlled for age, height, fat mass, self-rated health and physical activity, plus maximum grip strength, the composite physical function score, or lear } \\
\text { mass }\end{array}$} \\
\hline \multicolumn{4}{|c|}{$\begin{array}{l}\text { f Model 3: Controlled for age, height, fat mass, self-rated health and physical activity, plus maximum grip strength/arms LM, composite physical function score/ } \\
\text { legs LM, or lean mass index }\end{array}$} \\
\hline \multirow{2}{*}{\multicolumn{4}{|c|}{$\begin{array}{l}{ }^{g} \text { Lean mass index models were not adjusted for height since height }{ }^{2} \text { is the denominator of the outcome } \\
* \mathrm{p}<.05\end{array}$}} \\
\hline \multicolumn{2}{|l|}{$* p<.05$} & & \\
\hline \multicolumn{4}{|l|}{ ** $\mathrm{p}<.01$} \\
\hline *** $p<.001$ & & & \\
\hline
\end{tabular}

loss of strength is greater than muscle mass, [30,31] as we observed in this study. This suggests that muscle quality may be reduced with aging, although as noted previously, this study did not have data to test this. If loss of muscle is the sole factor responsible for age declines or racial/ethnic group differences in muscle strength or physical function, then relative strength measures should not differ according to age or race/ethnicity. This explanation is not consistent with the observations in this study. Racial/ethnic differences in lower extremity physical function were observed even after indexing for lower extremity lean mass, as observed in other studies [20]. In analyses not shown, lean mass accounted for only a small portion of observed age differences in muscle strength, which is consistent with some studies [32-35] but not others [30,36-39]. These discrepancies could relate to the observation that age declines in measures of relative 
muscle strength may depend on how muscle mass is estimated and the study design [31].

Limitations to the current study should be acknowledged. First, the cross-sectional design of the study is problematic, limiting our ability give a true estimate of age trends. Second, the dynamometer used in this and many other epidemiologic studies does not measure maximal voluntary strength, which is a superior measure of muscle strength. An obvious limitation to the current study is the lack of data on specific endpoints of interest (e.g., fracture, disability, mortality), limiting our ability to examine whether observed differences in the musclerelated factors examined "explain" racial/ethnic differences in these endpoints. Finally, subjects were not asked to perform the tandem balance test, the third component of the short physical performance battery of Guralnik et al. [19] In addition, the cutpoints for the walk and chair stand test established by Guralnik et al. were not used in this report. This has been done previously with this measure by us [40] and others [41] and also for similar constructs $[42,43]$. Given the generally high levels of function of the population under study, the use of these established cutpoints induces a ceiling effect in this data set. This limitation is partially offset by the observation that the modified composite physical function score correlates well with theoretically related variables included in this analysis (age, self-rated health, and physical activity), and the appeal of the composite physical function score as a global measure of physical function.

\section{Conclusions}

In conclusion, these data on racial/ethnic differences in lean mass and physical function, when considered as a whole, appear to be broadly consistent with known racial/ethnic differences in outcomes. Further exploration of why higher lean mass in non-white subjects do not appear to translate into higher strength and physical function is warranted. The observations reported herein could have implications for clinical trials as well as public health. These data raise interesting questions regarding the choice of endpoints in clinical trials given that our data on upper extremity strength suggest that the amount of muscle required to generate a given force may differ in important ways across individuals or groups of individuals. Our findings also have implications for public health. Racial/ethnic population subgroups are growing at varying rates, with non-white populations in the US growing more rapidly. For instance, the US Hispanic population represented approximately $12 \%$ of the population in 2000 and will represent $24 \%$ of the population in 2050 . This means that the lower levels of physical function observed among black and Hispanic men, insofar as this may translate into higher rates of physical disability and its associated consequences, could result in increased health care costs as the age distribution of these population subgroups shifts towards an older age.

\section{Acknowledgements}

The project described was supported by Award Number R01AG020727 from the National Institute on Aging. The parent study (BACH) was supported by grant U01DK056842 from the National Institute of Diabetes and Digestive and Kidney Diseases. Analyses for the current manuscript were supported in part through an unrestricted educational grant to New England Research Institutes, Inc. from GlaxoSmithKline. REW and RVC are employees of, and have equity interest in, GlaxoSmithKline. The content is solely the responsibility of the authors and does not necessarily represent the official views of the National Institute on Aging, the National Institute of Diabetes and Digestive and Kidney Diseases, the National Institutes of Health, or GlaxoSmithKline

\section{Author details}

${ }^{1}$ New England Research Institutes, Inc., Watertown, MA, USA.

${ }^{2}$ GlaxoSmithKline, Collegeville, PA, USA. ${ }^{3}$ GlaxoSmithKline Research and Development, Research Triangle Park, NC, USA.

\section{Authors' contributions}

All authors 1) made substantial contributions to conception and design, acquisition of data, or analysis and interpretation of data; 2) drafted the article or revised it critically for important intellectual content; and 3) provided final approval of the version submitted.

\section{Authors' Information}

NA

\section{Competing interests}

A.B.A., G.R.C., V.K., S.A.H., and J.B.M. received funding for analysis and write-up of the current manuscript from GlaxoSmithKline. R.E.W. and R.V.C. are employees of, and have equity interest in, GlaxoSmithKline.

Received: 11 December 2009 Accepted: 21 August 2010 Published: 21 August 2010

\section{References}

1. Beaufrere B, Morio B: Fat and protein redistribution with aging: metabolic considerations. Eur J Clin Nutr 2000, 54(Suppl 3):S48-53.

2. Di lorio A, Abate M, Di Renzo D, Russolillo A, Battaglini C, Ripari P, Saggini R, Paganelli R, Abate G: Sarcopenia: age-related skeletal muscle changes from determinants to physical disability. Int J Immunopathol Pharmacol 2006, 19(4):703-719.

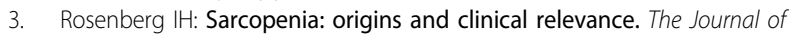
nutrition 1997, 127(5 Suppl):990S-991S.

4. Flynn MA, Nolph GB, Baker AS, Krause G: Aging in humans: a continuous 20-year study of physiologic and dietary parameters. Journal of the American College of Nutrition 1992, 11(6):660-672.

5. Gallagher D, Visser M, De Meersman RE, Sepulveda D, Baumgartner RN, Pierson RN, Harris T, Heymsfield SB: Appendicular skeletal muscle mass: effects of age, gender, and ethnicity. J App/ Physiol 1997, 83(1):229-239.

6. Baumgartner RN, Koehler KM, Gallagher D, Romero L, Heymsfield SB, Ross RR, Garry PJ, Lindeman RD: Epidemiology of sarcopenia among the elderly in New Mexico. American journal of epidemiology 1998, 147(8):755-763.

7. Baumgartner RN, Waters DL, Gallagher D, Morley JE, Garry PJ: Predictors of skeletal muscle mass in elderly men and women. Mech Ageing Dev 1999, 107(2):123-136.

8. Baumgartner RN: Body composition in healthy aging. Annals of the New York Academy of Sciences 2000, 904:437-448.

9. Ferrucci L, Guralnik JM, Pahor M, Corti MC, Havlik RJ: Hospital diagnoses, Medicare charges, and nursing home admissions in the year when older persons become severely disabled. Jama 1997, 277(9):728-734.

10. Janssen I, Shepard DS, Katzmarzyk PT, Roubenoff R: The healthcare costs of sarcopenia in the United States. Journal of the American Geriatrics Society 2004, 52(1):80-85. 
11. Janssen I: Influence of sarcopenia on the development of physical disability: the Cardiovascular Health Study. Journal of the American Geriatrics Society 2006, 54(1):56-62.

12. Kamel HK: Sarcopenia and aging. Nutr Rev 2003, 61(5 Pt 1):157-167.

13. Kinney JM: Nutritional frailty, sarcopenia and falls in the elderly. Curr Opin Clin Nutr Metab Care 2004, 7(1):15-20.

14. Morley JE, Baumgartner RN, Roubenoff R, Mayer J, Nair KS: Sarcopenia. J Lab Clin Med 2001, 137(4):231-243.

15. Rice DP, LaPlante MP: Medical expenditures for disability and disabling comorbidity. American journal of public health 1992, 82(5):739-741.

16. Araujo AB, Travison TG, Harris SS, Holick MF, Turner AK, McKinlay JB: Race/ ethnic differences in bone mineral density in men. Osteoporos Int 2007, 18(7):943-953.

17. McKinlay JB, Link CL: Measuring the urologic iceberg: design and implementation of the Boston Area Community Health (BACH) Survey. Eur Urol 2007, 52(2):389-396.

18. Washburn RA, Smith KW, Jette AM, Janney CA: The Physical Activity Scale for the Elderly (PASE): development and evaluation. Journal of clinical epidemiology 1993, 46(2):153-162.

19. Guralnik JM, Simonsick EM, Ferrucci L, Glynn RJ, Berkman LF, Blazer DG, Scherr PA, Wallace RB: A short physical performance battery assessing lower extremity function: association with self-reported disability and prediction of mortality and nursing home admission. Journal of gerontology 1994, 49(2):M85-94.

20. Newman AB, Haggerty CL, Goodpaster B, Harris T, Kritchevsky S, Nevitt M, Miles TP, Visser M: Strength and muscle quality in a well-functioning cohort of older adults: the Health, Aging and Body Composition Study. Journal of the American Geriatrics Society 2003, 51(3):323-330.

21. Cochran WG: Sampling techniques New York: John Wiley \& Sons, 31977.

22. Hastie TJ, Tibshirani RJ: Generalized additive models Boca Raton: Chapman and Hall/CRC 1990

23. Dunlop DD, Song J, Manheim LM, Daviglus ML, Chang RW: Racial/ethnic differences in the development of disability among older adults. American journal of public health 2007, 97(12):2209-2215.

24. Mendes de Leon CF, Beckett LA, Fillenbaum GG, Brock DB, Branch LG, Evans DA, Berkman LF: Black-white differences in risk of becoming disabled and recovering from disability in old age: a longitudinal analysis of two EPESE populations. American journal of epidemiology 1997, 145(6):488-497.

25. Mendes de Leon CF, Barnes LL, Bienias JL, Skarupski KA, Evans DA: Racial disparities in disability: recent evidence from self-reported and performance-based disability measures in a population-based study of older adults. The journals of gerontology 2005, 60(5):S263-271.

26. Chumlea WC, Guo SS, Kuczmarski RJ, Flegal KM, Johnson CL, Heymsfield SB, Lukaski HC, Friedl K, Hubbard VS: Body composition estimates from NHANES III bioelectrical impedance data. Int J Obes Relat Metab Disord 2002, 26(12):1596-1609.

27. Obisesan TO, Aliyu MH, Bond V, Adams RG, Akomolafe A, Rotimi CN: Ethnic and age-related fat free mass loss in older Americans: the Third National Health and Nutrition Examination Survey (NHANES III). BMC Public Health 2005, 5(1):41.

28. Looker AC, Wahner HW, Dunn WL, Calvo MS, Harris TB, Heyse SP, Johnston CC, Lindsay R: Updated data on proximal femur bone mineral levels of US adults. Osteoporos Int 1998, 8(5):468-489.

29. Marshall LM, Zmuda JM, Chan BK, Barrett-Connor E, Cauley JA, Ensrud KE, Lang TF, Orwoll ES: Race and ethnic variation in proximal femur structure and BMD among older men. J Bone Miner Res 2008, 23(1):121-130.

30. Frontera WR, Hughes VA, Lutz KJ, Evans WJ: A cross-sectional study of muscle strength and mass in 45- to 78-yr-old men and women. J Appl Physiol 1991, 71(2):644-650.

31. Metter EJ, Lynch N, Conwit R, Lindle R, Tobin J, Hurley B: Muscle quality and age: cross-sectional and longitudinal comparisons. J Gerontol A Biol Sci Med Sci 1999, 54(5):B207-218.

32. Davies $C T$, Thomas DO, White MJ: Mechanical properties of young and elderly human muscle. Acta Med Scand Suppl 1986, 711:219-226.

33. Reed RL, Pearlmutter L, Yochum K, Meredith KE, Mooradian AD: The relationship between muscle mass and muscle strength in the elderly. Journal of the American Geriatrics Society 1991, 39(6):555-561.

34. Vandervoort AA, McComas AJ: Contractile changes in opposing muscles of the human ankle joint with aging. J Appl Physiol 1986, 61(1):361-367.
35. Young A, Stokes $M$, Crowe M: The size and strength of the quadriceps muscles of old and young men. Clin Physiol 1985, 5(2):145-154.

36. Mansell PI, Rawlings J, Allison SP, Bendall MJ, Pearson M, Bassey EJ, Bastow M: Low anthropometric indices in elderly females with fractured neck of femur. Clin Nutr 1990, 9(4):190-194.

37. Overend TJ, Cunningham DA, Kramer JF, Lefcoe MS, Paterson DH: Knee extensor and knee flexor strength: cross-sectional area ratios in young and elderly men. Journal of gerontology 1992, 47(6):M204-210.

38. Pearson MB, Bassey EJ, Bendall MJ: The effects of age on muscle strength and anthropometric indices within a group of elderly men and women. Age and ageing 1985, 14(4):230-234.

39. Young A, Stokes M, Crowe M: Size and strength of the quadriceps muscles of old and young women. Eur J Clin Invest 1984, 14(4):282-287.

40. Araujo AB, Travison TG, Bhasin S, Esche GR, Williams RE, Clark RV, McKinlay JB: Association between testosterone and estradiol and agerelated decline in physical function in a diverse sample of men. Journal of the American Geriatrics Society 2008, 56(11):2000-2008.

41. Schaap LA, Pluijm SM, Deeg DJ, Penninx BW, Nicklas BJ, Lips P, Harris TB, Newman AB, Kritchevsky SB, Cauley JA, et al: Low testosterone levels and decline in physical performance and muscle strength in older men: findings from two prospective cohort studies. Clinical endocrinology 2008, 68(1):42-50.

42. Cawthon PM, Marshall LM, Michael Y, Dam TT, Ensrud KE, Barrett-Connor E, Orwoll ES: Frailty in older men: prevalence, progression, and relationship with mortality. Journal of the American Geriatrics Society 2007 55(8):1216-1223

43. Ensrud KE, Ewing SK, Taylor BC, Fink HA, Cawthon PM, Stone KL, Hillier TA, Cauley JA, Hochberg MC, Rodondi N, et al: Comparison of 2 frailty indexes for prediction of falls, disability, fractures, and death in older women. Arch Intern Med 2008, 168(4):382-389.

\section{Pre-publication history}

The pre-publication history for this paper can be accessed here: http://www.biomedcentral.com/1471-2458/10/508/prepub

doi:10.1186/1471-2458-10-508

Cite this article as: Araujo et al:: Lean mass, muscle strength, and physical function in a diverse population of men: a population-based cross-sectional study. BMC Public Health 2010 10:508.

\section{Submit your next manuscript to BioMed Central and take full advantage of:}

- Convenient online submission

- Thorough peer review

- No space constraints or color figure charges

- Immediate publication on acceptance

- Inclusion in PubMed, CAS, Scopus and Google Scholar

- Research which is freely available for redistribution 